\title{
DISEASE AND TREATMENT FEATURES AND EXPECTATIONS IN THE BRAZILIAN COHORT OF SENSE, A LARGE INTERNATIONAL STUDY IN RHEUMATOID ARTHRITIS
}

Mariana Peixoto Guimarães U. Silva Souza ${ }^{1}$, Ricardo Acayaba de Toledo², Anna Maura Fernandes ${ }^{3}$, Maysa Silva Arruda ${ }^{4, *}$, Andrea Caroline $\mathrm{Nardo}^{4}$, Antônio Scafuto Scotton ${ }^{5}$

1. Santa Casa de Misericórdia de Belo Horizonte, Belo Horizonte (BH), Brazil. 2. Fundação Faculdade Regional de Medicina de São José do Rio Preto, São José do Rio Preto (SP), Brazil. 3. Hospital Estadual Mário Covas, Santo André (SP), Brazil. 4. Abbvie Farmacêutica Ltda, São Paulo (SP), Brazil. 5. Centro Mineiro de Pesquisa, Juiz de Fora (MG), Brazil.

*Corresponding author: maysa.arruda@abbvie.com

\section{BACKGROUND}

Patient characteristics, treatment preferences and goals are important determinants of treatment success in rheumatoid arthritis (RA). SENSE, a noninterventional, cross-sectional study conducted among adult patients with RA and moderate or high disease activity, aimed to assess associations between inadequate response to disease-modifying antirheumatic drugs (DMARDs), patient attitudes, and disease outcomes in 18 countries. This study presents selected results of SENSE Brazilian cohort.

\section{MATERIALS AND METHODS}

Patient satisfaction was assessed by Treatment Satisfaction Questionnaire for Medication (TSQM), version 1.4. Treatment adherence, patient preferences, and expectations were evaluated by visual analog scales. Digital health literacy was assessed using eHealth Literacy Scale. Work Productivity and Activity Impairment Questionnaire-Rheumatoid Arthritis, v2.0 (WPAI-RA) was used to assess workability. Quality of life was assessed using 36-Item Short Form Survey (SF-36), version 2.

\section{RESULTS}

Of 1624 patients in SENSE, 73 were from Brazil and 70 were analyzed. Most were female (87.1\%), the median age was 58.5 years, and median disease duration was 8 years. The mean (SD) disease activity was 4.9 (1.2) by DAS28-CRP, and the HAQ-DI of 1.4 (0.8) indicated a moderate to severe impact on functional ability. No patients were in remission and 7 patients (10.0\%) were in LDA by CDAl. Current medication included methotrexate (72.9\% of patients), glucocorticoids (45.7\%), leflunomide (25.7\%), biologic DMARDs (22.9\%), and tofacitinib (5.7\%); one/two/three DMARDs were taken by 68.6/27.1/4.3\% of patients, respectively. The mean self-reported treatment adherence was 89.1\%. The mean (SD) TSQM subscores were 55.5 (22.4) for effectiveness; 85.4 (24.2) for side effects; 72.7 (19.5) for convenience; and 66.9 (19.8) for global satisfaction. The leading treatment expectations were "general improvement of arthritis", "less joint pain", and "lasting relief of RA symptoms", with SD of 5.6-5.7 (1.8). A total of $65.7 \%$ of patients preferred oral administration and $41.4 \%$ preferred not to use drug combinations for RA. Mean SF-36 subscores ranged from 34.6 to 60.0 . Only $30 \%$ of patients were employed, and the SD were 50.7 (34.7) for total work productivity impairment and 59.3 (32.7) for total activity impairment. The SD Total eHealth Literacy score was 21.1 (8.8), and only $40 \%$ of patients found internet useful or very useful to make health decisions.

\section{CONCLUSION}

These results, generally congruent with those from SENSE overall, suggest that disease control remains suboptimal, and quality of life and productivity are considerably affected, among patients with moderate or severe RA. Among such patients, better disease control may lead to improvements of such outcomes. 


\section{REFERENCES}

1. Ruberth-Roth A, Enejosa J, Pangan A, Xavier R, Haroui B, Rischmueller M, et al. Efficacy and safety of upadacitinib versus abatacept in patients with active rheumatoid arthritis and prior inadequate response or intolerance to biologic disease-modifying anti-rheumatic drugs (select-choice): a double-blind, randomized controlled phase 3 trial. Ann Rheum Dis. 2020; 79(suppl1):1011.

\section{DISCLOSURES OF INTEREST}

1. Mariana Peixoto Guimarães U. Silva Souza: Grant/research support: GSK, BMS, Abbvie, UCB, Pfizer; Consultant of: Janssen, Abbvie, Novartis; Educational support/Speakers bureau: Abbvie, Pfizer, UCB, Janssen, Roche.

2. Ricardo Acayaba de Toledo: Grant/research support: Abbvie, GSK, BMS, Novartis, Pfizer; Speakers bureau: Abbvie, Apsen, Janssen, Novartis, Pfizer, UCB; Consultant of: Janssen, Abbvie; Educational support: Abbvie, Novartis, Janssen, Pfizer

3. Anna Maura Fernandes: Grant/research support: Abbvie, Roche, Genentech, GSK, PR Pharma; Educational support: Abbvie, Novartis, Jansen, Pfizer, SANOFI; Speakers bureau: Novartis.

4. Maysa Silva Arruda - Abbvie Brazil employee.

5. Andrea Carolina Nardo - Abbvie Brazil employee.

6. Antônio Scafuto Scotton: Grant/research support: Abbvie, Roche, Novartis, Janssen, Astra Zeneca, Servier, Lilly, GSK, Pfizer, Bristol, Novonordisk; Consultant of: Abbvie, Novartis, Janssen 